\title{
Editorial \\ Special Issue: State of the Art in Research on Acupuncture Treatment
}

\author{
Younbyoung Chae ${ }^{1, *(1)}$, Myeong Soo Lee ${ }^{2}(\mathbb{D})$ and Yi-Hung Chen ${ }^{3}(\mathbb{D})$ \\ 1 Acupuncture and Meridian Science Research Center, Kyung Hee University, Seoul 02447, Korea \\ 2 Clinical Medicine Division, Korea Institute of Oriental Medicine, Daejeon 34054, Korea; drmslee@gmail.com \\ 3 Graduate Institute of Acupuncture Science, China Medical University, Taichung 40402, Taiwan; \\ yihungchen@mail.cmu.edu.tw \\ * Correspondence: ybchae@khu.ac.kr
}

Citation: Chae, Y.; Lee, M.S.; Chen, Y.-H. Special Issue: State of the Art in Research on Acupuncture Treatment. J. Clin. Med. 2021, 10, 5943. https:// doi.org/10.3390/jcm10245943

Received: 10 December 2021

Accepted: 14 December 2021

Published: 17 December 2021

Publisher's Note: MDPI stays neutral with regard to jurisdictional claims in published maps and institutional affiliations.

Copyright: (C) 2021 by the authors. Licensee MDPI, Basel, Switzerland. This article is an open access article distributed under the terms and conditions of the Creative Commons Attribution (CC BY) license (https:/ / creativecommons.org/licenses/by/ $4.0 /)$.
Acupuncture is a medical treatment that involves inserting a needle into the body. Since acupuncture-related techniques and knowledge spread in the West in the 1970s, this treatment has become used and validated for many disorders [1]. Acupuncture stimulation influences target organs via the central and peripheral nervous systems [2]. Functional neuroimaging studies have provided new clues to the neural mechanisms of acupuncture treatment in various diseases [3,4]. Artificial intelligence technology has recently shed light on new approaches to advance acupuncture research [5]. Machine learning can discover connections between diseases and recommended acupoints from large-scale clinical data in the age of artificial intelligence [6,7].

This issue includes 14 articles on the current status of acupuncture research in South Korea, Taiwan, the United States, Poland, and the Czech Republic. It consists of 11 original research articles based on various approaches (e.g., clinical trials, neuroimaging, and machine learning), and 3 review articles that discuss the state of the field and inspire efforts to acquire new insights into acupuncture therapeutics.

The three reviews in this issue outline the present status of acupuncture, cupping therapy, and moxibustion. Using an animal model of post-traumatic stress disorder, a comprehensive review outlines the processes underlying acupuncture [8]. Evidencemapping methods are used to show the available data in a systematic review of cupping therapy for several illnesses [9]. A bibliometric study reveals the time-based evolution of moxibustion research, as well as the global network of relevant research hubs [10].

The clinical applications of acupuncture and related therapies in this issue include pain management during head and neck cancer radiotherapy [11], chemotherapy-induced peripheral neuropathy in breast cancer patients [12], acute whiplash injury [13], spinal stenosis [14], and poor ovarian function [15]. Resting-state functional neuroimaging studies show the neural underpinnings of acupuncture treatment of primary dysmenorrhea [16] and lower back pain [17]. Furthermore, neuroimaging-based scalp acupuncture suggests dementia therapy locations [18].

Two data-driven approaches reveal acupoint selection and acupoint indication characteristics. Machine learning techniques uncover the commonality and diversity in acupoint selection [19]. Reverse inference and Bayesian factor analyses help discover the specificities of acupoint indications from clinical trial datasets [20]. When artificial intelligence is combined with a wealth of clinical data on acupuncture treatment, connections between diseases and acupoints can be discovered.

We hope that our readers will enjoy this issue of the Journal of Clinical Medicine, which extends our knowledge of acupuncture clinical trials and supports the mechanisms of this form of treatment. We believe that with the help of data science technologies, the principles of acupoint selection can be better identified. 
Funding: This research was supported by Korea Institute of Oriental Medicine (KSN1812181) and the National Research Foundation of Korea (NRF) funded by the Ministry of Science, ICT \& Future Planning (No. 2021R1F1A1046705).

Conflicts of Interest: The authors declare no conflict of interest.

\section{References}

1. Lee, I.S.; Lee, H.; Chen, Y.H.; Chae, Y. Bibliometric Analysis of Research Assessing the Use of Acupuncture for Pain Treatment Over the Past 20 Years. J. Pain Res. 2020, 13, 367-376. [CrossRef] [PubMed]

2. Napadow, V.; Beissner, F.; Lin, Y.; Chae, Y.; Harris, R.E. Editorial: Neural Substrates of Acupuncture: From Peripheral to Central Nervous System Mechanisms. Front. Neurosci. 2019, 13, 1419. [CrossRef] [PubMed]

3. Chae, Y.; Chang, D.S.; Lee, S.H.; Jung, W.M.; Lee, I.S.; Jackson, S.; Kong, J.; Lee, H.; Park, H.J.; Lee, H.; et al. Inserting needles into the body: A meta-analysis of brain activity associated with acupuncture needle stimulation. J. Pain 2013, 14, 215-222. [CrossRef] [PubMed]

4. Zhang, J.; Zhang, Y.; Hu, L.; Huang, X.; Liu, Y.; Li, J.; Hu, Q.; Xu, J.; Yu, H. Global Trends and Performances of Magnetic Resonance Imaging Studies on Acupuncture: A Bibliometric Analysis. Front. Neurosci. 2020, 14, 620555. [CrossRef] [PubMed]

5. Chae, Y. Suggestions for the study of acupoint indications in the era of artificial intelligence. J. Physiol. Pathol. Korean Med. 2021, 35, 132-138.

6. Hwang, Y.C.; Lee, Y.S.; Ryu, Y.; Lee, I.S.; Chae, Y. Statistical inference of acupoint specificity: Forward and reverse inference. Integr. Med. Res. 2020, 9, 17-20. [CrossRef] [PubMed]

7. Jung, W.M.; Park, I.S.; Lee, Y.S.; Kim, C.E.; Lee, H.; Hahm, D.H.; Park, H.J.; Jang, B.H.; Chae, Y. Characterization of hidden rules linking symptoms and selection of acupoint using an artificial neural network model. Front. Med. 2019, 13, 112-120. [CrossRef] [PubMed]

8. Kwon, C.Y.; Lee, B.; Kim, S.H. Efficacy and Underlying Mechanism of Acupuncture in the Treatment of Posttraumatic Stress Disorder: A Systematic Review of Animal Studies. J. Clin. Med. 2021, 10, 1575. [CrossRef] [PubMed]

9. Choi, T.Y.; Ang, L.; Ku, B.; Jun, J.H.; Lee, M.S. Evidence Map of Cupping Therapy. J. Clin. Med. 2021, 10, 1750. [CrossRef] [PubMed]

10. Park, H.; Lee, I.S.; Lee, H.; Chae, Y. Bibliometric Analysis of Moxibustion Research Trends over the Past 20 Years. J. Clin. Med. 2020, 9, 1254. [CrossRef] [PubMed]

11. Szmit, M.; Agrawal, S.; Gozdzik, W.; Kubler, A.; Agrawal, A.; Pruchnicki, P.; Woźniak, M.; Nowak, M.; Bartoszewicz, B.; Rudnicki, J. Transcutaneous Electrical Acupoint Stimulation Reduces Postoperative Analgesic Requirement in Patients Undergoing Inguinal Hernia Repair: A Randomized, Placebo-Controlled Study. J. Clin. Med. 2021, 10, 146. [CrossRef]

12. Huang, C.C.; Ho, T.J.; Ho, H.Y.; Chen, P.Y.; Tu, C.H.; Huang, Y.C.; Lee, Y.C.; Sun, M.F.; Chen, Y.H. Acupuncture Relieved Chemotherapy-Induced Peripheral Neuropathy in Patients with Breast Cancer: A Pilot Randomized Sham-Controlled Trial. J. Clin. Med. 2021, 10, 3694. [CrossRef]

13. Kim, D.; Park, K.S.; Lee, J.H.; Ryu, W.H.; Moon, H.; Park, J.; Jeon, Y.H.; Seo, J.Y.; Moon, Y.J.; Namgoong, J.; et al. Intensive Motion Style Acupuncture Treatment (MSAT) Is Effective for Patients with Acute Whiplash Injury: A Randomized Controlled Trial. J. Clin. Med. 2020, 9, 2079. [CrossRef]

14. Kim, D.; Shin, J.S.; Moon, Y.J.; Ryu, G.; Shin, W.; Lee, J.; Lim, S.; Jeon, H.A.; Seo, J.Y.; Wang, W.H.; et al. Long-Term Follow-Up of Spinal Stenosis Inpatients Treated with Integrative Korean Medicine Treatment. J. Clin. Med. 2020, 10, 74. [CrossRef] [PubMed]

15. Kim, J.; Lee, H.; Choi, T.Y.; Kim, J.I.; Kang, B.K.; Lee, M.S.; Joo, J.K.; Lee, K.S.; You, S. Acupuncture for Poor Ovarian Response: A Randomized Controlled Trial. J. Clin. Med. 2021, 10, 2182. [CrossRef] [PubMed]

16. Tu, C.H.; Lee, Y.C.; Chen, Y.Y.; Chen, C.M.; Lu, W.C.; Chen, Y.H.; Yang, S.T. Acupuncture Treatment Associated with Functional Connectivity Changes in Primary Dysmenorrhea: A Resting State fMRI Study. J. Clin. Med. 2021, 10, 4731. [CrossRef] [PubMed]

17. Yu, S.; Ortiz, A.; Gollub, R.L.; Wilson, G.; Gerber, J.; Park, J.; Huang, Y.; Shen, W.; Chan, S.T.; Wasan, A.D.; et al. Acupuncture Treatment Modulates the Connectivity of Key Regions of the Descending Pain Modulation and Reward Systems in Patients with Chronic Low Back Pain. J. Clin. Med. 2020, 9, 1719. [CrossRef] [PubMed]

18. Cao, J.; Huang, Y.; Meshberg, N.; Hodges, S.A.; Kong, J. Neuroimaging-Based Scalp Acupuncture Locations for Dementia. J. Clin. Med. 2020, 9, 2477. [CrossRef] [PubMed]

19. Jang, D.Y.; Oh, K.C.; Jung, E.S.; Cho, S.J.; Lee, J.Y.; Lee, Y.J.; Kim, C.E.; Yang, I.J. Diversity of Acupuncture Point Selections According to the Acupuncture Styles and Their Relations to Theoretical Elements in Traditional Asian Medicine: A Data-MiningBased Literature Study. J. Clin. Med. 2021, 10, 2059. [CrossRef] [PubMed]

20. Hwang, Y.C.; Lee, I.S.; Ryu, Y.; Lee, Y.S.; Chae, Y. Identification of Acupoint Indication from Reverse Inference: Data Mining of Randomized Controlled Clinical Trials. J. Clin. Med. 2020, 9, 3027. [CrossRef] [PubMed] 